\title{
A Multi-Criteria Decision Making Approach for Machine Tool Selection Problem in a Fuzzy Environment
}

\author{
Arzum Özgen \\ Department of Industrial Engineering, Okan University, \\ Akfirat, Tuzla, Istanbul 34959, Turkey \\ E-mail: arzum.eser@okan.edu.tr \\ Gülfem Tuzkaya ${ }^{1}$ \\ Department of Industrial Engineering, Yildiz Technical University \\ Barbaros Street, Yildiz, Istanbul 34349, Turkey \\ E-mail: gtuzkaya@yildiz.edu.tr \\ Umut R. Tuzkaya \\ Department of Industrial Engineering, Yildiz Technical University \\ Barbaros Street, Yildiz, Istanbul 34349, Turkey \\ E-mail: tuzkaya@yildiz.edu.tr \\ Doğan Özgen \\ Department of Industrial Engineering, Yildiz, Technical University \\ Barbaros Street, Yildiz, Istanbul 34349, Turkey \\ E-mail:dozgen@yildiz.edu.tr \\ Received 12 June 2010 \\ Accepted 21 January 2011
}

\begin{abstract}
Tools and machines have an important effect on the manufacturing operations' effectiveness and the selection process of appropriate tools and machines is a complex issue with the consideration of multiple criteria. Considering the complexity of the problem area and the difficulties in machine tools evaluation processes, the main purpose of this study is to present a novel and effective methodology for machine tool selection problem. The proposed methodology constituted for this aim combines the modified DELPHI method, AHP (Analytical Hierarchy Process) and PROMETHEE (Preference Ranking Organization METHod for Enrichment Evaluations) approaches with fuzzy sets theory to be able to reflect the vagueness related to judgment of the decision-maker(s). A real life application is realized for pressing machine selection problem of a fixing products manufacturer from Turkey, Istanbul. The results of the proposed approach are compared with the results of fuzzy AHP-fuzzy TOPSIS approach. Additionally, sensitivity analyses are realized to show the changes in the results with the change in the criteria weights.
\end{abstract}

Keywords: Machine tool selection; modified DELPHI method; AHP; PROMETHEE; fuzzy sets

${ }^{1}$ Corresponding author: e-mail: gtuzkaya@yildiz.edu.tr, phone: +90 2123832919 


\section{Introduction}

Selection of the proper machine tools is a very critical aspect for the machining processes of the products. The production quality, speed, flexibility, etc. are being affected by machining processes' performance. Dramatic problems could be occurring in production performance as a result of a weak decision making process in machine tool selection. Considering its importance, a large body of studies conducted by researchers for machine tool selection (MTS) problems. Multi-criteria decision making (MCDM) techniques in the evaluation processes of machine tools have been found proper by most of the researchers of this scope. AHP (Analytic Hierarchy Process), ANP (Analytic Network Process), TOPSIS (Technique of Order Preference by Similarity to Ideal Solution), ELECTRE (ELimination Et Choix Traduisant la REalitéElimination and choice expressing reality) and PROMETHEE (Preference Ranking Organization METHod for Enrichment Evaluations) could be counted among in the mostly utilized MCDM techniques for machine tool selection problem.

When the related literature is investigated, it is observed that almost the most preferred MCDM technique for the machine tool selection problem is AHP. Some of the studies using AHP can be summarized as follows. Tabucanon et al. [1] have used the AHP technique for the selection process of flexible manufacturing systems (FMS). Chan et al. [2] have described the development of an intelligent material handling equipment selection system. This system has constituted from three modules; a database, knowledge based expert system and an AHP model. AHP is utilized to help knowledge based expert system to choose most suitable equipment system. They have also used artificial intelligence in decision making process. Yurdakul [3] has presented a strategic justification tool for the evaluation of investments in machine tools. AHP and ANP are applied in calculation of the contributions of machine tool alternatives. Chang et al. [4] have discussed and developed a manufacturing quality yield model for forecasting silicon wafer slicing based on the AHP framework. Çimren et al. [5] have proposed a decision support system for MTS problem using AHP.

As can be observed from the literature, AHP's systematic decision making way for MCDM problems was widely utilized in the current MTS literature. However, like as the most of the other real life problems, for MTS problem, it is hard to obtain numerical judgments for the alternatives from the experts. Additionally, for most of the considered criteria, it is hard to make certain judgements due to the fuzzy structure of the decision environment. In order to have the ability of taking linguistic preferences and taking into account the fuzziness of the environment, researchers have started to use fuzzy sets in recent years. Fuzzy AHP is one of the mostly utilized techniques which are taking into account the fuzziness of the environment. Some of the MTS studies using fuzzy AHP can be summarized as follows. Ayağ and Özdemir [6] have selected fuzzy AHP method developed by Saaty [7]. They have used a fuzzy AHP methodology for considering the vagueness and uncertainty existing in the judgment of the decisionmaker(s). Önüt et al. [8] proposed a machine tool selection methodology in which criteria weights are determined via fuzzy AHP. Chang et al. [9] have proposed a new approach within the AHP framework for tackling the uncertainty and imprecision of silicon wafer slicing evaluations during manufacturing process stages where the decision-makers' comparison judgements are represented as triangular fuzzy numbers (TFN). Duran and Aguillo [10] have used an AHP based approach with fuzzy numbers for the evaluation and justification of an advanced manufacturing system. An example of MTS problem is used to illustrate and validate the proposed approach. Abdi [11] has investigated reconfigurable machining system characteristics in order to identify the crucial factors influencing the machine selection and the machine (re)configuration. In particular, a fuzzy AHP model is proposed to integrate the decisive factors for the equipment selection process under uncertainty. Ayağ and Özdemir [12] proposed a machine tool selection methodology under uncertainty using an improved version of AHP which is Analytical Network Process (ANP).

In spite of the fact that AHP and fuzzy AHP are the mostly utilized techniques in MTS literature, as Dagdeviren [13] stated, with these techniques, evaluations can be made using the same evaluation scale and preference functions on the criteria basis. Definition of different reference functions for the criteria is an important factor which affects the correctness of the decision made. Unlike other ranking methods in the literature, different preference functions can be defined 
for criteria in PROMETHEE method [13]. It is a ranking method which is quite simple in conception and application compared to other methods for MCDM. It is well adapted to problems where a finite number of alternative actions are to be ranked considering several, sometimes conflicting criteria [14]. According to Ülengin et al. [15], advantages of PROMETHEE can be summarized as: (i) PROMETHEE is a user friendly outranking method, (ii) it has been successfully applied to real life planning problems and (iii) PROMETHEE I and PROMETHEE II allow both partial and total ranking of the alternatives while still satisfying simplicity.

In MTS literature, Dağdeviren [13] have integrated AHP and PROMETHEE techniques for the equipment selection problem. However in that study, the vagueness of the decision environment was not taken into account. Different from this study, in that paper, vagueness of the environment and advantages coming from utilizing linguistic scales are taken into account by using fuzzy sets. Another study is realized by Tuzkaya et al. [16] for the material handling equipment selection problem and utilized an integrated fuzzy ANP-fuzzy PROMETHEE approach. In that study, fuzziness of the environment was taken into account, however, in criteria determination phase, a systematic approach was not utilized. Different from Tuzkaya et al. [16], in this study, criteria determination phase is a more structured process with the help of modified DELPHI technique. In this paper, we have considered pressing machine tool selection process for a pipe clamps manufacturing company from the Turkish construction sector. The current pressing machines of Inka Fixing are old versions and breakdown frequency is very high and management team is considering new pressing machine investments. For the machine tool selection problem of Inka Fixing, considering the easiness of linguistic evaluations and vagueness of the decision environment, using fuzzy set theory is found proper. Also, consideration of multiple criteria such as investment cost, flexibility, user friendliness etc. is found convenient and in the criteria determination phase, modified DELPHI method is utilized. In the criteria weights' calculations, fuzzy AHP is utilized and with the obtained weights of criteria, alternative machine tools are evaluated via fuzzy PROMETHEE methodology. In the second section of this study, detailed information related to utilized methodologies is given. Also proposed integrated decision methodology has described in this section. In the third section, application of proposed integrated model in Inka fixing company has presented. The application of modified Delphi method in criteria determination phase and detailed information about each selected criteria are given. Related calculations, comparison with fuzzy AHP-fuzzy TOPSIS technique, analysis of results with sensitivity analyses are also presented. In the final section, some concluding remarks are presented.

\section{Proposed Approach for Machine Tool Selection Problem 2.1 Preliminaries}

\subsubsection{Modified DELPHI method}

The Delphi method accumulates and analyzes the results of anonymous experts that communicate in written, discussion and feedback formats on a particular topic. Anonymous experts share knowledge skills, expertise and opinions until a mutual consensus is achieved $[17 ; 18 ; 19]$. The steps of Delphi method can be explained as [19]: (1) select the anonymous experts; (2) conduct the first round of a survey; (3) conduct the second round of a questionnaire survey; (4) conduct the third round of a questionnaire survey; and (5) integrate expert opinions in order to reach a consensus. Steps (3) and (4) are normally repeated until a consensus is reached on a particular topic [19]. The modified Delphi technique is similar to the full Delphi in terms of procedure and intent. The major modification consists of beginning the process with a set of carefully selected items. These pre-selected items may be drawn from various sources including related competency profiles, synthesized reviews of the literature, and interviews with selected content experts [20]. Results of the literature review and expert interviews can be used to identify and synthesize all common views expressed in the survey. Moreover, step (2) is simplified to replace the conventionally adopted open style survey; doing so is commonly referred to as the modified Delphi method [21]. The primary advantages of this modification to the Delphi is that it (a) typically improves the initial round response rate, and (b) provides a solid grounding in previously developed work. Additional advantages related to the use of the modified Delphi technique include reducing the effects of bias due to group interaction, assuring anonymity, and providing 
controlled feedback to participants [20]. In general, the decision-making group probably should not be too large, i.e. a minimum of five to a maximum of about 50 [22]. Murry and Hammons [23] suggested that the modified Delphi method summarize expert opinions on a range from 10 to 30 [19]. In this study, 14 experts' opinions are taken into account as modified Delphi method-based expert group.

\subsubsection{Fuzzy sets}

Some definitions of fuzzy sets related to this study are given as follows.

Definition 1. A fuzzy set $\tilde{A}$ in a universe of discourse $X$ is characterized by membership function $\mu_{\tilde{A}}(X)$, which associates with each element $x$ in $X$, a real number in the interval $[0,1]$. The function $\mu_{\tilde{A}}(X)$ is termed the grade of membership of $\mathrm{x}$ in $\tilde{A}$ [24].

Definition 2. A TFN can be defined as a triplet $\left(a^{l}, a^{m}\right.$, $\left.a^{u}\right)$; the membership function of the fuzzy number $\tilde{A}$ is defined as follows [25].

$$
f_{\tilde{A}}(x)=\left\{\begin{array}{lc}
0, & x<a^{l}, \\
\left(x-a^{l}\right) /\left(a^{m}-a^{l}\right), & a^{l} \leq x \leq a^{m}, \\
\left(a^{u}-x\right) /\left(a^{u}-a^{m}\right), & a^{m} \leq x \leq a^{u}, \\
0, & x>a^{u} .
\end{array}\right\}
$$

Operational laws of TFNs can be found in [25].

Definition 3. A linguistic variable is a variable whose values are linguistic terms [24].

The concept of linguistic variable is very useful in dealing with situations which are too complex or too illdefined to be reasonably described in conventional quantitative expressions. These linguistic variables can also be represented by fuzzy numbers [24].

\subsubsection{AHP- Fuzzy AHP}

The Analytical Hierarchy Process (AHP), developed by Saaty [7], is one of the MCDM approaches that decomposes a complex problem to a hierarchical order and has been used by various researchers for decisionmaking in production systems $[26 ; 27 ; 28 ; 29]$. The fuzzy logic could be added to the classical AHP to take into account the vague nature of a certain decision making area $[30 ; 31]$.

In the fuzzy AHP, to evaluate the decision makers' preferences, pair-wise comparisons are structured using triangular fuzzy numbers $\left(a^{l}, a^{m}, a^{u}\right)$. The mxn fuzzy matrix can be given as in Equation (2). The element $\tilde{a}_{i j}$ represents the comparison of the component $i$ (row element) with component $j$ (column element). If $\tilde{A}$ is a pair-wise comparison matrix (see Equation (8)), it is assumed that the reciprocal, and the reciprocal value, i.e. $1 / \tilde{a}_{i j}$, is assigned to the element $\tilde{a}_{i j}$ [32].

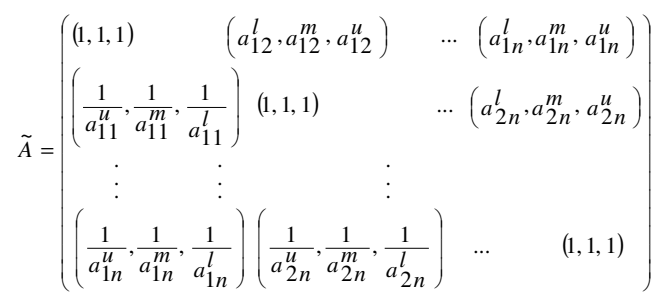

$\tilde{A}$ is also a triangular, fuzzy, pair-wise comparison matrix. There are several methods for getting estimates for the fuzzy priorities, $\tilde{w}_{i}$, where $\tilde{w}_{i}=\left(w_{i}^{l}, w_{i}^{m}, w_{i}^{u}\right)$, and $i=1,2, \ldots, n$, from the judgement matrix, $\tilde{A}$, which approximates the fuzzy ratios $\tilde{a}_{i j}$, so that $\tilde{a}_{i j} \approx \tilde{w}_{i} / \tilde{w}_{j}$. One of these methods, the logarithmic least-squares method, is used in this study since it is a most-used and effective method. The triangular fuzzy weights representing the relative importance of the criteria, the feedback of the criteria and the alternatives according to individual criteria is calculated by this method. The logarithmic least-squares method for calculating triangular fuzzy weights can be given as follows [32]:

$$
\tilde{w}_{i}=\left(w_{i}^{l}, w_{i}^{m}, w_{i}^{u}\right), \mathrm{k}=1,2, \ldots, \mathrm{n} .
$$

where

$$
w_{i}^{s}=\frac{\left(\prod_{j=1}^{n} a_{i j}^{s}\right)^{1 / n}}{\sum_{k=1}^{n}\left(\prod_{j=1}^{n} a_{k j}^{m}\right)^{1 / n}}, \quad s \in\{l, m, u\} .
$$

The alternatives are evaluated as previously explained. Following this step, for converting the weights of the alternatives to crisp numbers, four different defuzzification methods are utilized: Chang's extent analysis [30] method, Center of Area (COA) method [33], Center of Gravity (COG) method [34] and Yager Index [35]. One of the most commonly used techniques for defuzzification is Chang's extent analysis method. The steps of Chang's extent analysis approach can be found in [36].

Center of Area (COA) method was developed by Sugeno in 1985. This method is also one of the most commonly used defuzzification techniques. COA technique can be expressed as [33]:

$$
x^{*}=\frac{\int \mu_{i}(x) x d x}{\int \mu_{i}(x) d x}
$$


where $x^{*}$ is the defuzzified output, $\mu_{i}(x)$ is the aggregated membership function and $\mathrm{x}$ is the output variable. The only disadvantage of this method is that it is computationally difficult for complex membership functions.

Another defuzzification method, Center of Gravity (COG) method, calculates the center of each triangle for the corresponding membership functions using the following equation [34]:

$$
x^{*}=\left(a^{l}+a^{m}+a^{u}\right) / 3
$$

where $x^{*}$ is the defuzzified output and $a^{l}, a^{m}$ and $a^{u}$ are the lower, medium and upper values of a TFN.

The last defuzzification method which is utilized in this paper is Yager Index [35] and it is simply calculated by Equation (6).

$$
x^{*}=\left(3 * a^{m}-\left(a^{m}-a^{l}\right)+\left(a^{u}-a^{m}\right)\right) / 3
$$

where $x^{*}$ is the defuzzified output and $a^{l}, a^{m}$ and $a^{u}$ are the lower, medium and upper values of a triangular fuzzy number.

\subsubsection{PROMETHEE-Fuzzy PROMETHEE}

PROMETHEE (Preference Ranking Organization METHod for Enrichment Evaluations) is an outranking method which initial references are prepared by Brans et al. [37], Brans and Vincle [38] and Brans et al. [39]. It is a quite simple ranking method in conception and application compared with other methods used for multi-criteria analysis. It is well adapted to the problems where a finite set of alternatives are to be ranked according to several, sometimes conflicting criteria [13; $16 ; 40]$.

The evaluation is the starting point of PROMETHEE method. In this phase, alternatives are evaluated with respect to different criteria. These evaluations involve essentially numerical data. The implementation of PROMETHEE requires two additional types of information, namely [41]:

- Information on the relative importance (i.e. the weights) of the criteria considered,

- Information on the decision-makers' preference function, which he/she uses when comparing the contribution of the alternatives in terms of each separate criterion.

The basic steps of the PROMETHEE algorithm can be outlined as follows [39; 42]:
Step 1. Specify a generalized preference function $p_{j}(d)$ for each criterion $j$. (see Figure 2).

Step 2. Define a vector containing the weights, which are a measure for the relative importance of each criterion, $w^{T}=\left[w_{1}, \ldots, w_{k}\right]$. If all the criteria are of the same importance in the opinion of the decision maker, all weights can be taken as being equal. The normalization of the weights, $\sum_{k=1}^{K} w_{k}=1$, is not necessarily required.

Step 3. Define for all the alternatives $a_{t}, a_{t^{\prime}} \in A$ the outranking relation $\pi$ :

$$
\pi:\left\{\begin{array}{l}
A x A \rightarrow[0,1] \\
\pi\left(a_{t}, a_{t}\right)=\sum_{k=1}^{K} w_{k} \cdot\left(p_{k}\left(f_{k}\left(a_{t}\right)-f_{k}\left(a_{t}\right)\right)\right.
\end{array}\right.
$$

The preference index $\pi\left(a_{t}, a_{t^{\prime}}\right)$ is a measure for the intensity of preference of the decision maker for an alternative $a_{t}$ in comparison with an alternative $a t^{\prime}$ for the simultaneous consideration of all criteria. It is basically a weighted average of the preference functions, $p_{k}(d)$ and can be represented as a valued outranking graph.

Step 4. As a measure for the strength of alternatives $a_{t} \in A$, the leaving flow is calculated:

$$
\Phi^{+}\left(a_{t}\right)=\frac{1}{T-1} \cdot \sum_{\substack{t^{\prime}=1 \\ t^{\prime} \neq t}}^{n} \pi\left(a_{t}, a_{t^{\prime}}\right)
$$

The leaving flow is the sum of the values of the arcs which leave node $a_{t}$ and therefore yields a measure of the "outranking character" of $a_{t}$.

Step 5. As a measure for the weakness of the alternatives, $a_{t} \in A$, the entering flow is calculated, measuring the "outranked character" of $a_{t}$ (analogously to the leaving flow):

$$
\left.\Phi^{-}\left(a_{t}\right)=\frac{1}{T-1} \cdot \sum_{\substack{t^{\prime}=1 \\ t^{\prime} \neq t}}^{n} \pi\left(a_{t^{\prime}}, a_{t}\right)\right)
$$

Step 6. A graphical evaluation of the outranking relation is derived: Basically, the higher the leaving flow and the lower the entering flow, the better the action. This result is graphically represented by a partial preorder (PROMETHEE I) or a complete preorder (PROMETHEE II).

In PROMETHEE I, alternative $a_{t}$ is preferred to alternative $a_{t},\left(a_{t} P a_{t}\right)$ at least one of the elements of Equation (10) is satisfied [13]: 
if

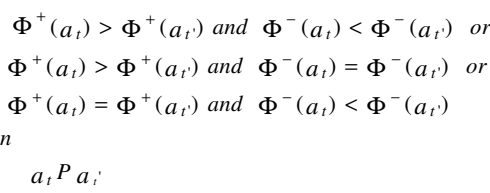

PROMETHEE I evaluation allows indifference and incomparability situations. Therefore sometimes partial rankings can be obtained. In the indifference situation $\left(a_{t} I a_{t^{\prime}}\right)$, two alternatives, $a_{t}$ and $a_{t}$, have the same leaving and entering flows $[13 ; 44]$ :

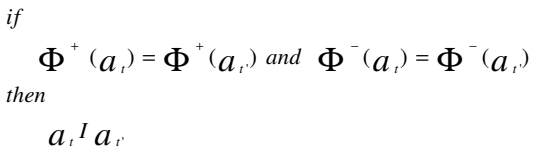

Two alternatives are considered incomparable, $a_{t} R a_{t}$, if alternative $a_{t}$ is better than alternative $a_{t}$, in terms of leaving flow, while the entering flows indicate the reverse [13]:

$$
\begin{aligned}
& \text { if } \\
& \Phi^{+}\left(a_{t}\right)>\Phi^{+}\left(a_{t}\right) \text { and } \Phi^{-}\left(a_{t}\right)>\Phi^{-}\left(a_{t}\right) \text { or } \\
& \Phi^{+}\left(a_{t}\right)<\Phi^{+}\left(a_{t}\right) \text { and } \Phi^{-}\left(a_{t}\right)<\Phi^{-}\left(a_{t}\right)
\end{aligned}
$$

Via PROMETHE II, the complete ranking can be obtained. For the complete ranking calculations, net flow values of alternatives can be calculated as Equation (13). Here, if alternative $a_{t}$ 's net flow is bigger that alternative $a_{t}$ 's net flow, this indicates that, alternative $a_{t}$ outranks alternative $a_{t}$.

$$
\Phi^{n e t}\left(a_{t}\right)=\Phi^{+}\left(a_{t}\right)-\Phi^{-}\left(a_{t}\right)
$$

In this study, the fuzzy PROMETHEE technique is preferred because of the fuzzy nature of the decision problem. In the literature, there are a few studies using fuzzy PROMETHEE approach. Bilsel et al. [14], Geldermann et al.[42], Goumas and Lygerou [45], Chou et al. [46], Tuzkaya et al. [16], Tuzkaya et al. [47] have used fuzzy PROMETHEE previously.

In the fuzzy PROMETHEE, the main problem arises in comparing two fuzzy numbers and the index, which corresponds to a weighted average of the fuzzy numbers, proposed from Yager (1981) is found a useful way to compare fuzzy numbers. It is determined by the center of weight of the surface representing its membership function $[14 ; 45]$. Based on the Yager's index [35], a TFN's magnitude is the value corresponding to the center of the triangle and can be expressed as in Equation (6). The representation of a TFN from here, $\tilde{F}=(n, a, b)$, is a different version of the representation used in $A H P$ and fuzzy AHP section. This is equivalent to the previous representation by $\tilde{F}=(n-a, n, n+b)$. The following fuzzy PROMETHEE formulas are based on the representation of TFN as

$(n, a, b)$.

In this study, PROMETHEE's linear preference function with indifference and strict preference is preferred for each criterion by Decision Making Team (DMT). In this preference function, two thresholds, $q$ and $p$ are needed to be determined (Figure 1). When using the fuzzy numbers in PROMETHEE, the evaluation function explained in Figure 1, can be converted to Equation (14).

$$
P_{j}\left(a_{t}, a_{t}\right)=\left\{\begin{array}{l}
0, \text { if } n-a \leq q(\text { indifference }) \\
\frac{(n, a, b)-q}{p-q}, \text { if } q \leq(n-a) \text { and }(n+b) \leq p \\
1, \text { if } n+b>p(\text { strict preference })
\end{array}\right.
$$

In Equation (14), $q$ and $p$ values are crisp numbers and the membership functions of the fuzzy number,

$C\left(a_{t}, a_{t}\right)=(n, a, b)$ is adjusted accordingly so that $n-a>=0$ and $n+b<=1$. In the if-statement in Equation (14), the controls are the TFNs which represents the differences between $a_{t}, a_{t}$. Similarly to the PROMETHEE approach, the leaving flow, the entering flow and the net flow notions are valid in the case of fuzzy PROMETHEE [14]. Outside of the above mentioned differences, fuzzy PROMETHEE utilizes from the PROMETHEE's application steps [16]. In these steps, for the operations with fuzzy numbers, the basic operators referenced in the "Fuzzy sets" section can also be used.

\subsection{Proposed Approach: An integrated fuzzy multi-criteria decision making methodology}

In this study, a novel integrated modified DELPHIfuzzy AHP-fuzzy PROMETHEE methodology is utilized. This methodology is initialized with the modified Delphi method for the determination of decision criteria. The weights of the decision criteria are determined via a fuzzy AHP approach. Obtained weights are utilized in the press machine alternatives' evaluation process. This process is realized via the fuzzy PROMETHEE methodology. The results are analyzed via sensitivity analyses. Finally, the results are proposed to the Decision Making Team (DMT) and the management of the company (Figure 2). 


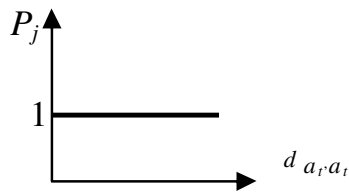

$P_{j}\left(a_{t}, a_{t^{\prime}}\right)= \begin{cases}0 & \text { if } d_{a t, a t^{\prime}} \leq 0 \text { (indifference) } \\ 1 & \text { if } d_{a t, a t^{\prime}}>0 \text { (strict preference) }\end{cases}$

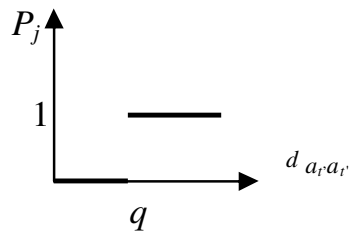

$P_{j}\left(a_{t}, a_{t^{\prime}}\right)=\left\{\begin{array}{l}0 \text { if } d_{a t, a t^{\prime}} \leq q \text { (indifferene) } \\ 1 \text { if } d_{a_{t}, a_{t^{\prime}}}>q(\text { strict preference) }\end{array}\right.$

Type 3: Criterion with linear preference (V-Shape)

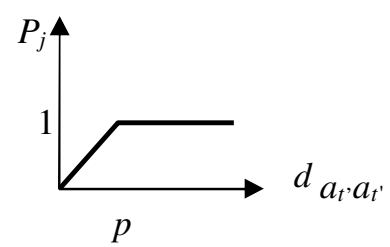

Type 4: Level criterion

$P_{j}\left(a_{t}, a_{t^{\prime}}\right)=\left\{\begin{array}{l}\frac{d_{a t, a t^{\prime}}}{p}, \text { if } 0<d_{a_{t}, a t^{\prime}} \leq p(\text { indifference) } \\ 1, \text { if } d_{a t, a t^{\prime}}>p(\text { strict preference) }\end{array} \quad P_{j}\left(a_{t}, a_{t^{\prime}}\right)=\left\{\begin{array}{l}0 \text { if } 0<d_{a_{t}, a t^{\prime}} \leq q \text { (indifference) } \\ 0.5, \text { if } q<d_{a_{t}, a t^{\prime}} \leq p \\ 1, \text { if } d_{a t, a t^{\prime}}>p \text { (strict preference) }\end{array}\right.\right.$

Type 5: Criterion with linear preference and indifference area

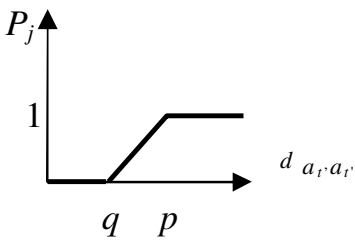

$$
P_{j}\left(a_{t}, a_{t^{\prime}}\right)=\left\{\begin{array}{l}
0, \text { if } d_{a t, a t^{\prime}} \leq q(\text { indifference }) \\
\frac{d_{a t, a t^{\prime}}-q}{p-q}, \text { if } q<d_{a t, a t^{\prime}} \leq p \\
1, \text { if } d_{a_{t}, a^{\prime}}>p(\text { strict preference })
\end{array}\right.
$$

Type 6: Gaussian criterion

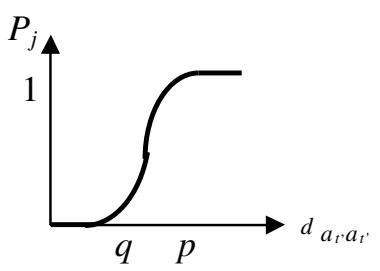

$P_{j}\left(a_{t}, a_{t^{\prime}}\right)=\frac{e^{x}}{1+e^{x}}$

Figure 1. PROMETHEE generalized preference functions $[39 ; 43 ; 44]$ 


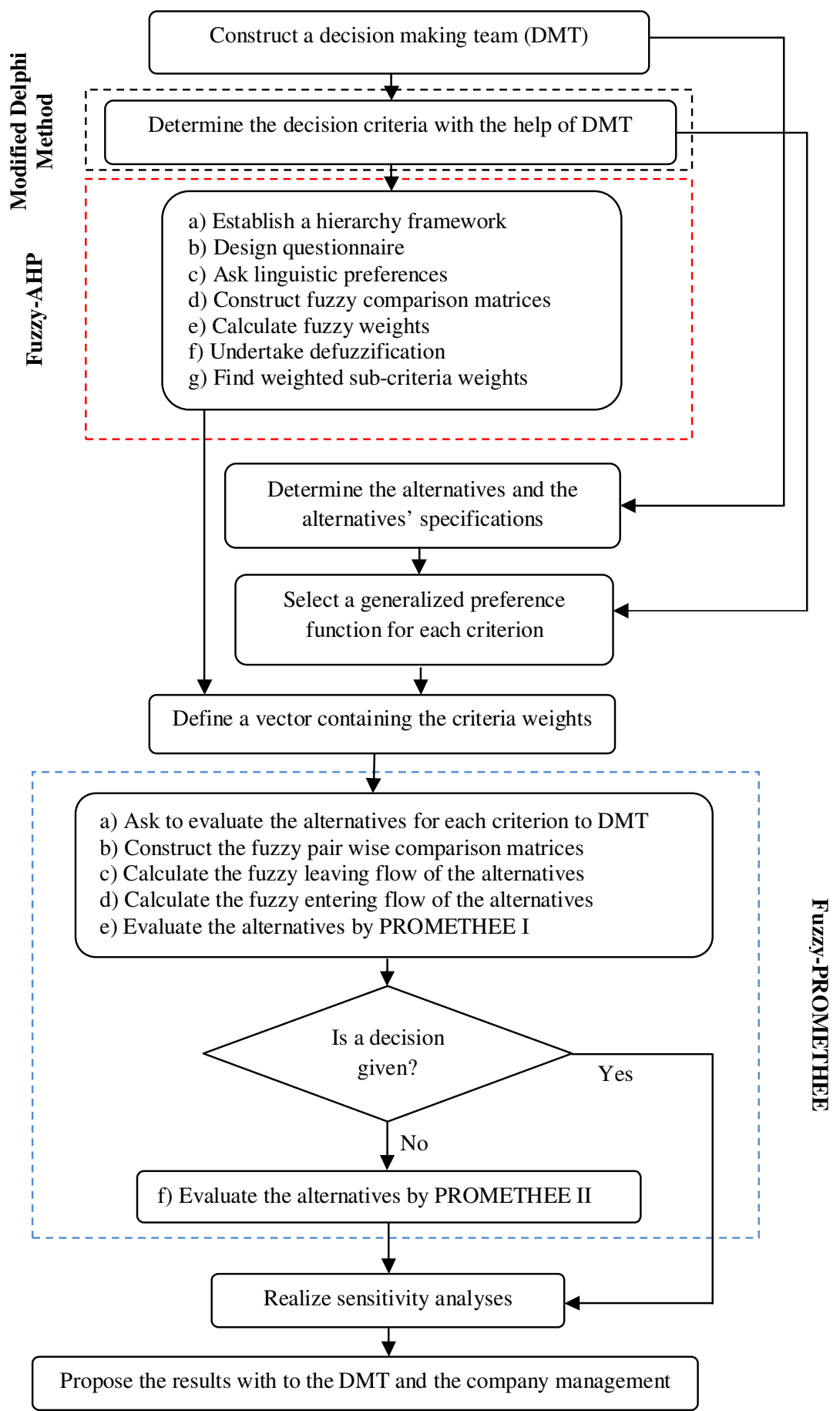

Figure 2. Proposed integrated fuzzy multi-criteria decision making methodology

Published by Atlantis Press

Copyright: the authors 
In the fuzzy AHP, DMT is asked to compare the criteria considering the effects on achieving main goal. In this process, the linguistic scale shown in Table 1 and Figure 3 is utilized.

Table 1. Linguistic scale for importance [48]

\begin{tabular}{lll}
\hline $\begin{array}{l}\text { Linguistic scale for } \\
\text { importance }\end{array}$ & $\begin{array}{l}\text { Triangular } \\
\text { fuzzy scale }\end{array}$ & $\begin{array}{l}\text { Triangular fuzzy } \\
\text { reciprocal scale }\end{array}$ \\
\hline $\begin{array}{l}\text { Just equal (JE) } \\
\text { Equally important (EI) }\end{array}$ & $(1,1,1)$ & $(1,1,1)$ \\
$\begin{array}{l}\text { Weakly more } \\
\text { important (WMI) }\end{array}$ & $(1,3 / 2,2)$ & $(2 / 3,1,2)$ \\
$\begin{array}{l}\text { Strongly more } \\
\text { important (SMI) }\end{array}$ & $(3 / 2,2,5 / 2)$ & $(2 / 5,1 / 2,2 / 3)$ \\
$\begin{array}{l}\text { Very strongly more } \\
\text { important (VSMI) }\end{array}$ & $(2,5 / 2,3)$ & $(1 / 3,2 / 5,1 / 2)$ \\
$\begin{array}{l}\text { Absolutely more } \\
\text { important (AMI) }\end{array}$ & $(5 / 2,3,7 / 2)$ & $(2 / 7,1 / 3,2 / 5)$ \\
\hline
\end{tabular}

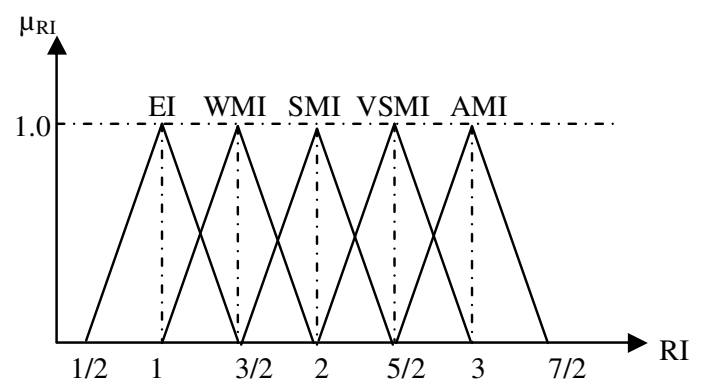

Figure 3. Linguistic scale for relative importance (RI) [48]

In the fuzzy PROMETHEE phase, the DMT is asked to evaluate alternatives considering each criterion. For this evaluation stage, the linguistic scale for relative importance is shown in Table 2 and Figure 4 is utilized. Table 2. Linguistic scale for evaluation [14]

\begin{tabular}{ll}
\hline Linguistic scale for evaluation & Triangular fuzzy scale \\
\hline Strongly disagree (SDA) & $(0,0,0.15)$ \\
Disagree (DA) & $(0,0.15,0.30)$ \\
Little disagree (LDA) & $(0.15,0.30,0.50)$ \\
No comment (NC) & $(0.30,0.50,0.65)$ \\
Little agree (LA) & $(0.50,0.65,0.80)$ \\
Agree (A) & $(0.65,0.80,1)$ \\
Strongly agree (SA) & $(0.80,1,1)$ \\
\hline
\end{tabular}

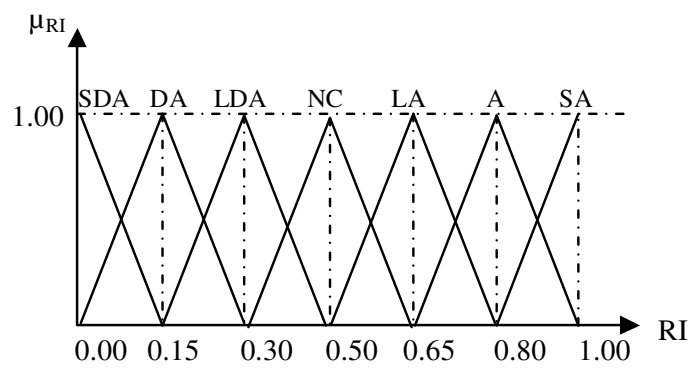

\section{An Application for a Manufacturing Company}

A real case study in the Inka Fixing Corporation from Istanbul is presented to foster the better understanding of the model. Inka Fixing is a pipe clamps manufacturer which produces three main groups of products: pipe clamps, anchors and hanging-fixing systems for constructing, heating and electronic sectors. In the manufacturing processes of Inka Fixing, machining methods such as pressing, welding and assembling are the main operations. An important portion of Inka Fixing's products consist of metal products such as pipe clamps with various sizes and types. The pipe clamps are manufactured via shaping the sheet iron. Pressing phase is an important step of sheet iron manufacturing process. Manufacturing imperfections mostly constituted in this step. Current pressing machines of Inka Fixing are old versions and breakdown frequency is very high. Production defects, breakdowns and maintenance costs make the management to think about new pressing machine investments. For this purpose, five alternatives are decided as candidates between all alternatives. The criteria for the decision process (Figure 5) are decided with a DMT constituted from 14 experts which are production manager, production engineers, finance managers, expert labors. In the criteria determination phase modified DELPHI method is utilized. Before starting the steps of modified DELPHI method, related literature, especially the papers which are summarized in the introduction section, is investigated and a pre-selected set of criteria is presented to the DMT.

Four main criteria that have their own sub-criteria are selected for the evaluation of machine tools. These main criteria could be summarized as Cost related specifications (C), Technical specifications (T), Operational specifications (O) and Quality related specifications $(\mathrm{Q})$.

C main criteria cluster contains all the cost issues such as investment costs, operating costs, maintenance costs and revision costs.

T main criteria cluster considers issues related capacity, setup and adjusting time, installation easiness and revision and upgrade ability. These sub-criteria are for measuring the effectiveness of the alternative machines. O main criteria cluster is related with the operational performance and specifications of the alternatives.

Figure 4. Linguistic scale for evaluation [14] 
These are flexibility, productivity, user friendliness and safety.

Q main criteria cluster contains the quality related issues such as accuracy, after sales maintenance, service possibilities and durability.

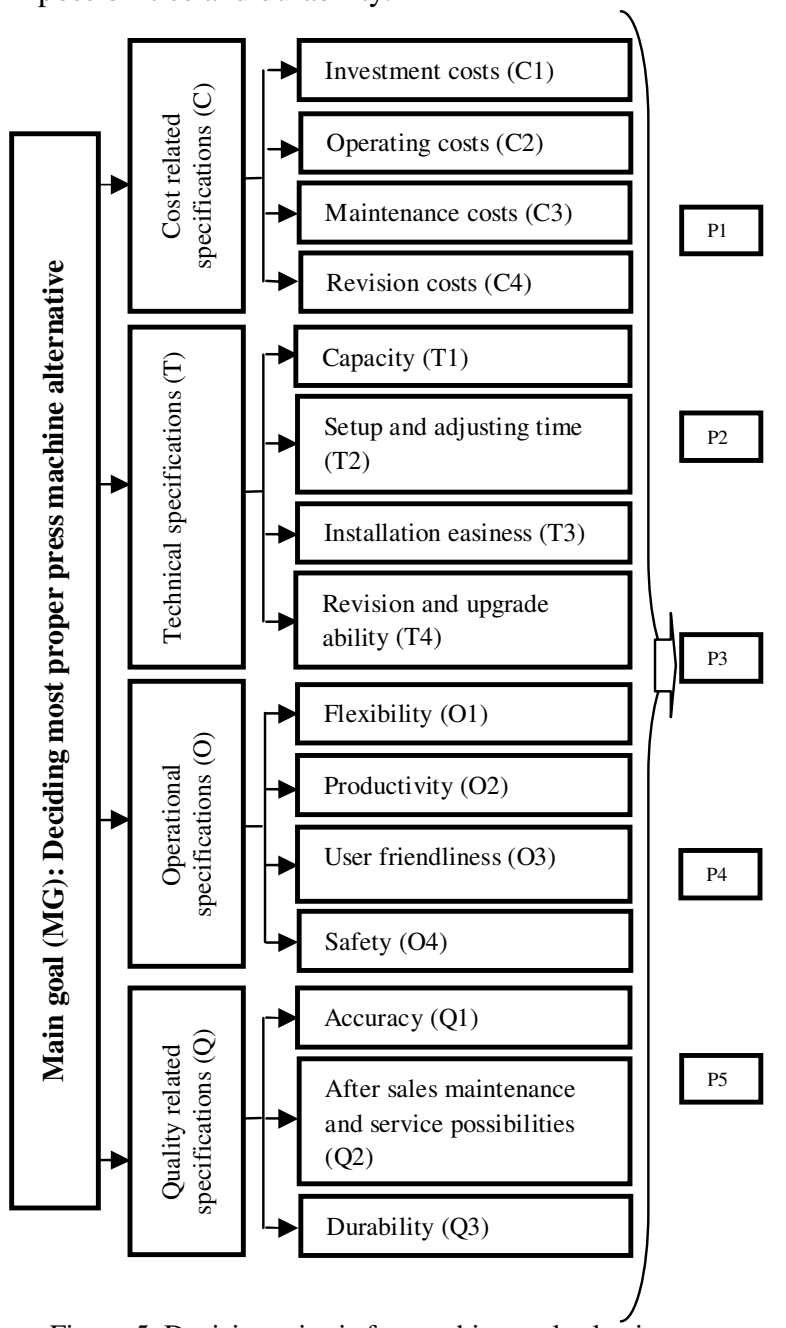

Figure 5. Decision criteria for machine tool selection process

After criteria determination phase via modified DELPHI method, criteria weights are determined via fuzzy AHP approach. This approach is begun with the comparison of main criteria with respect to contribution to the main goal's achievement. First, the comparisons are taken from DMT linguistically using linguistic expressions in Table 1 (Table 3).
Table 3. Linguistic main criteria comparisons considering the contribution to the achievement

\begin{tabular}{lllll}
\hline MG & C & T & O & Q \\
\hline $\mathbf{C}$ & JE & WMI & EI & WMI \\
$\mathbf{T}$ & WLI & JE & EI & EI \\
$\mathbf{O}$ & EI & EI & JE & WMI \\
$\mathbf{Q}$ & WLI & EI & WLI & JE \\
\hline
\end{tabular}

The linguistic comparisons shown in Table 3 are converted to triangular fuzzy numbers using the scale given in Table 1 and can be seen from Table 4.

Table 4. Main criteria comparisons considering the contribution to the achievement of main goal (with triangular fuzzy numbers)

\begin{tabular}{lllllll}
\hline & $\mathbf{C}$ & \multicolumn{5}{c}{$\mathbf{T}$} \\
\hline $\mathbf{C}$ & 1,00 & 1,00 & 1,00 & 1,00 & 1,50 & 2,00 \\
$\mathbf{T}$ & 0,50 & 0,67 & 1,00 & 1,00 & 1,00 & 1,00 \\
$\mathbf{O}$ & 0,67 & 1,00 & 2,00 & 0,67 & 1,00 & 2,00 \\
$\mathbf{Q}$ & 0,50 & 0,67 & 1,00 & 0,67 & 1,00 & 2,00 \\
& $\mathbf{O}$ & & & $\mathbf{Q}$ & & \\
$\mathbf{C}$ & 0,50 & 1,00 & 1,50 & 1,00 & 1,50 & 2,00 \\
$\mathbf{T}$ & 0,50 & 1,00 & 1,50 & 0,50 & 1,00 & 1,50 \\
$\mathbf{O}$ & 1,00 & 1,00 & 1,00 & 1,00 & 1,50 & 2,00 \\
$\mathbf{Q}$ & 0,50 & 0,67 & 1,00 & 1,00 & 1,00 & 1,00 \\
\hline
\end{tabular}

Using triangular fuzzy comparisons, criteria weights (Table 5) are calculated using Equation (2)-(3).

Table 5. Weights of main criteria (with triangular fuzzy numbers)

\begin{tabular}{lccc}
\hline & Lower value $\left(\boldsymbol{a}^{\boldsymbol{l}}\right)$ & Medium value $\left(\boldsymbol{a}^{\boldsymbol{m}}\right)$ & Upper value $\left(\boldsymbol{a}^{\boldsymbol{u}}\right)$ \\
\hline $\mathbf{C}$ & 0,84 & 1,22 & 1,57 \\
$\mathbf{T}$ & 0,59 & 0,90 & 1,22 \\
$\mathbf{O}$ & 0,82 & 1,11 & 1,68 \\
$\mathbf{Q}$ & 0,64 & 0,82 & 1,19 \\
\hline
\end{tabular}

Same steps are repeated for the sub-criteria comparisons with respect to their contributions to the achievement of related main criterion. For the defuzzification step, Chang's extent analysis (steps of Chang's extent analysis can be found in [36]), COA, CGA and Yager Index methods are utilized (Equation (4)-(5)-(6)). Almost the same results are obtained via COA, COG and Yager Index and very close results are obtained via Chang's extent analysis. Obtained main criteria, subcriteria and weighted sub-criteria weights via Yager Index are presented in Table 6. Also, consistency ratios of all AHP comparisons are calculated and found below 0.10 . 
Table 6. Main criteria weights (MCW), sub-criteria weights (SCW) and weighted sub-criteria weights (WSCW)

\begin{tabular}{llllllll}
\hline & MCW & & SCW & WSCW & & SCW & WSCW \\
\hline C & 0.29 & C1 & 0.30 & 0.09 & T1 & 0.39 & 0.08 \\
T & 0.22 & C2 & 0.33 & 0.09 & T2 & 0.26 & 0.06 \\
O & 0.29 & C3 & 0.23 & 0.07 & T3 & 0.18 & 0.04 \\
Q & 0.21 & C4 & 0.15 & 0.04 & T4 & 0.17 & 0.04 \\
\hline & \multicolumn{1}{c}{} & & SCW & WSCW & & SCW & WSCW \\
\hline & & O1 & 0.14 & 0.04 & Q1 & 0.45 & 0.09 \\
& & O2 & 0.26 & 0.07 & Q2 & 0.20 & 0.04 \\
& & O3 & 0.24 & 0.07 & Q3 & 0.35 & 0.07 \\
& & O4 & 0.37 & 0.10 & & & \\
\hline
\end{tabular}

As a first step of fuzzy PROMETHEE, DMT is asked to determine the generalized criterion type for each criterion. Level criterion type is selected for all criteria and $q$ and $p$ values are determined as 0.0 and 0.7, respectively.

Following the criteria type and weight determination phase, DMT is asked to evaluate alternatives linguistically (Table 7) considering the sub-criteria using Table 2. For the alternatives' evaluation process, the situation of each alternative, for each criterion is asked to the DMT. For example, for the investment cost (C1) criterion evaluation of the first machine (P1), the question asked to the DMT is "Do you agree that investment cost of P1 is in an affordable level?". Also for the after sale service and maintenance possibilities criterion $(\mathrm{O} 2)$ evaluation for first alternative, the DMT is asked to answer the question of "Do you agree that after acquisition of P1, after sales and maintenance needs of this machine are quickly and effectively tried to be solved by the sellers".

Table 7. Alternative press machine's evaluations considering the evaluation criteria

\begin{tabular}{lllllllll}
\hline & C1 & C2 & C3 & C4 & T1 & T2 & T3 & T4 \\
\hline P1 & DA & A & A & A & SA & A & LA & A \\
P2 & SA & A & NC & NC & A & LA & LA & NC \\
P3 & LA & A & LA & LA & A & A & LA & A \\
P4 & SA & DA & DA & DA & LDA & DA & DA & LDA \\
P5 & NC & NC & LA & LA & LDA & LDA & NC & NC \\
\hline & O1 & O2 & O3 & O4 & Q1 & Q2 & Q3 & \\
\hline P1 & SA & SA & A & SA & A & A & SA & \\
P2 & NC & NC & LA & NC & LA & LA & LA & \\
P3 & A & A & A & SA & A & LA & A & \\
P4 & DA & LDA & NC & NC & LDA & SDA & NC & \\
P5 & LA & LA & NC & LA & LDA & LDA & NC & \\
\hline
\end{tabular}

These linguistic evaluations (Table 7) are converted to triangular fuzzy numbers according to the scale shown in Table 2 and applying fuzzy PROMETHEE's steps, alternatives' positive, negative and net flows are calculated (Table 8).

Table 8. Positive, negative and net flows for the alternative

\begin{tabular}{lrrrrrrr} 
& \multicolumn{7}{c}{ press machines } \\
\cline { 2 - 7 } & P1 & P2 & P3 & P4 & P5 & $\boldsymbol{\Phi}^{+}$ & $\boldsymbol{\Phi}^{\text {net }}$ \\
\hline P1 & 0.00 & 0.24 & 0.00 & 0.82 & 0.51 & 1.56 & 1.35 \\
P2 & 0.09 & 0.00 & 0.03 & 0.49 & 0.26 & 0.87 & 0.49 \\
P3 & 0.09 & 0.14 & 0.00 & 0.85 & 0.43 & 1.51 & 1.47 \\
P4 & 0.00 & 0.00 & 0.00 & 0.00 & 0.00 & 0.00 & -2.42 \\
P5 & 0.04 & 0.00 & 0.00 & 0.27 & 0.00 & 0.31 & -0.89 \\
\hline $\boldsymbol{\Phi}^{-}$ & 0.21 & 0.38 & 0.03 & 2.42 & 1.20 & &
\end{tabular}

\subsection{Application results, analysis of the results and sensitivity analysis}

First of all, considering the positive and negative flow values of alternatives (Table 8), partial ranking is obtained via PROMETHEE I approach. Since, none of the conditions in Equation (10)-(11)-(12) are satisfied, P1 and P3 cannot be compared. In other words, since positive flow value of $\mathrm{P} 1$ is more than the positive flow value of P3 and negative flow value of P3 is less than the negative flow value of $\mathrm{P} 1, \mathrm{P} 1$ and $\mathrm{P} 3$ are found indifferent. On the other hand P1 and P3 outrank P2, P5 and $\mathrm{P} 4$. Other outranking relations can be seen from Figure 6.

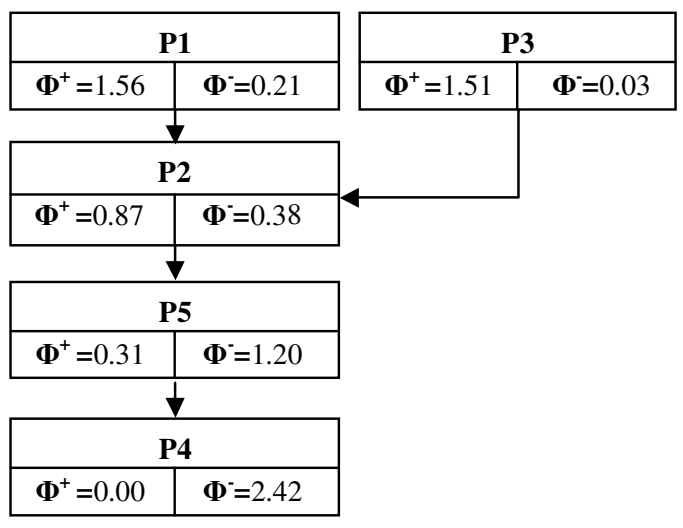

Figure 6. PROMETHEE I results for the alternative press machines

To obtain a full ranking for alternatives, net flows are calculated (Table 8) and alternatives are ranked via PROMETHEE II (Figure 7) using Equation (13). Alternatives which are found indifferent via 
PROMETHEE I, P1-P3, can be compared via PROMETHEE II. Considering the net flows, P3 outranks all the other alternatives and found as the best alternative with a very close evaluation degree to P1's net flow value.

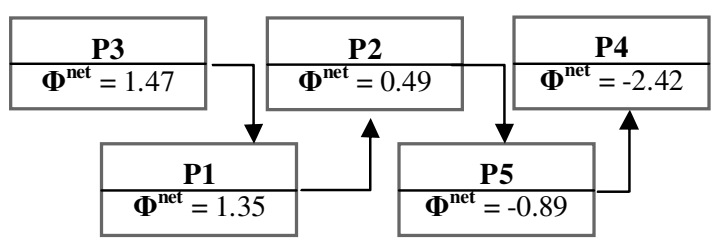

Figure 7. PROMETHEE II results for the alternative press machines

\subsubsection{Comparison of the results with the results of TOPSIS}

As mentioned in the introduction section, fuzzy PROMETHEE approach is preferred to utilize because of a number of reasons. However, to validate the ranking, fuzzy TOPSIS approach is applied to the same data and the results are compared as below. Details of the fuzzy TOPSIS approach can be found in Tuzkaya and Gülsün [49]. For the criteria weights, same evaluation results obtained via fuzzy AHP approach are utilized. The results obtained via fuzzy AHP-fuzzy TOPSIS approach can be summarized as in Table 9.

Table 9. Evaluation results via fuzzy AHP-fuzzy TOPSIS

\begin{tabular}{llll}
\hline & $\begin{array}{l}\text { Distance from } \\
\text { fuzzy positive } \\
\text { ideal solution } \\
\text { (DFPIS) }\end{array}$ & $\begin{array}{l}\text { Distance from } \\
\text { fuzzy negative } \\
\text { ideal solution } \\
\text { (DFNIS) }\end{array}$ & $\begin{array}{l}\text { Closeness } \\
\text { coefficient- } \\
\text { CC= DFNIS/ } \\
\text { (DFPIS+DFNIS) }\end{array}$ \\
\hline P1 & 0.24 & 0.69 & 0.74 \\
P2 & 0.37 & 0.54 & 0.60 \\
P3 & 0.25 & 0.68 & 0.73 \\
P4 & 0.71 & 0.21 & 0.23 \\
P5 & 0.51 & 0.40 & 0.44 \\
\hline
\end{tabular}

As can be seen from Table 9, the best alternative is found as P1. However, its evaluation degree is very close to P3. The ranking of alternatives is found as P1, P3, P2, P5 and P4 from best to worst. While, P1 and P3 cannot be compared via PROMETHEE I, the remaining ranking is same with TOPSIS evaluations. On the other hand, with a very small difference from P1, P3 is found better in PROMETHEE II evaluation results. As a result, it can be said that, the final outranking of the proposed approach gives very close solution to the fuzzy AHP-fuzzy TOPSIS approach. In the final decision process, DMT should also consider this small difference. It should be also noted that, via PROMETHEE approach, the criteria types can be determined different from each other among the generalized preference functions (Figure 1), also threshold values, $q$ and $p$, gives the opportunity to determine the degree of preference.

\subsubsection{Sensitivity Analysis}

As mentioned before, the weights of the decision criteria are determined via fuzzy AHP. In this stage, the sensitivity of the results to the changes in the criteria weights is analyzed. As an example for all other sensitivity analysis of criteria weights, here, only the results' sensitivity to the changes in cost criterion's weights is presented. From the Figure 8, changes on the alternatives' leaving flows as the change on the cost criterion's weight can be seen. As shown in this figure, at the point that cost criterion's weight is " 0 ", the leaving flow values of P1 and P3 take their maximum value, and the leaving flow values of P2 and P5 take their minimum value. While the weight of cost criterion increases, the leaving flow values of P1 and P3 decrease but $\mathrm{P} 2$ and $\mathrm{P} 5$ increase. The situation of $\mathrm{P} 4$ doesn't change with the change of weight in cost criterion. This indicates that for the cost criterion evaluations, the performances of $\mathrm{P} 1$ and $\mathrm{P} 3$ are worse than other alternatives.

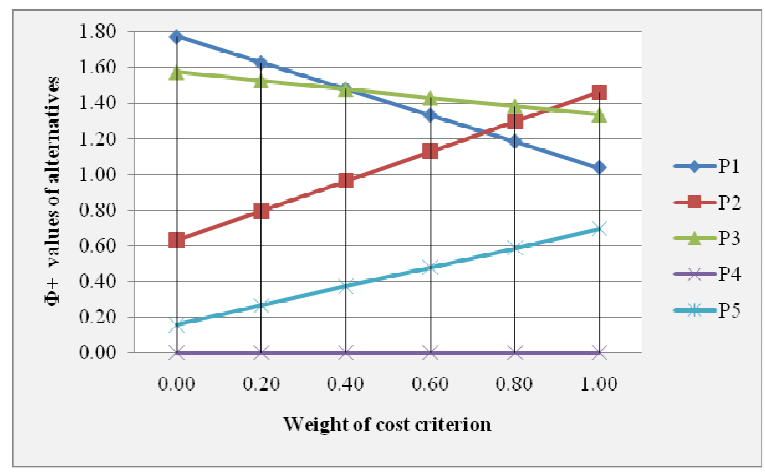

Figure 8 . The change in the $\Phi^{+}$values of alternatives with the change in the weight of cost criterion

When considering the entering flows, with the increase of the weight of cost criterion from " 0 " to " 1 ", the entering flow values of P1, P3 and P4 increase and the entering flow values of P2 and P5 decrease (Figure 9). This indicates that, for the cost criterion evaluations, the performances of P2 and P5 are better than the other alternatives. 


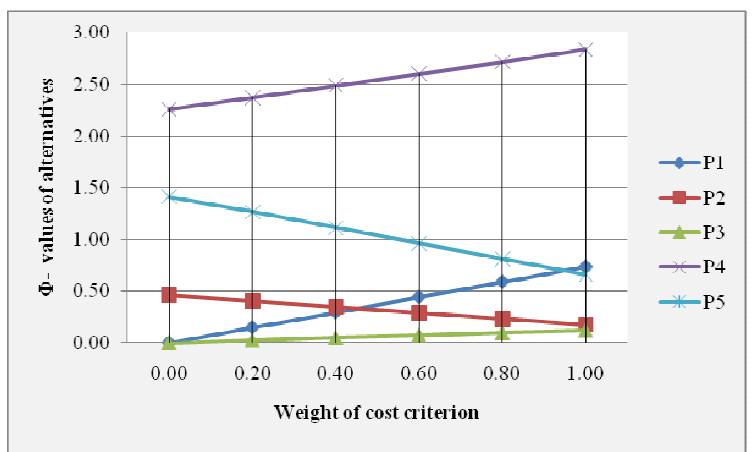

Figure 9. The change in the $\Phi^{-}$values of alternatives with the change in the weight of cost criterion

When considering the net flows, with the increase of the weight of cost criterion from " 0 " to " 1 ", the net flows of $\mathrm{P} 1, \mathrm{P} 3$ and $\mathrm{P} 4$ are getting worse, and the net flows of P2 and $\mathrm{P} 5$ are getting better (Figure 10). This is why, P1, P3 and P4's evaluations for cost criterion are below the average when comparing with the others and the increase on the cost criterion's weights amplifies this situation. This situation is parallel to the analysis of the sensitiveness of $\Phi^{+}$and $\Phi^{-}$values to the weight of the cost criterion.

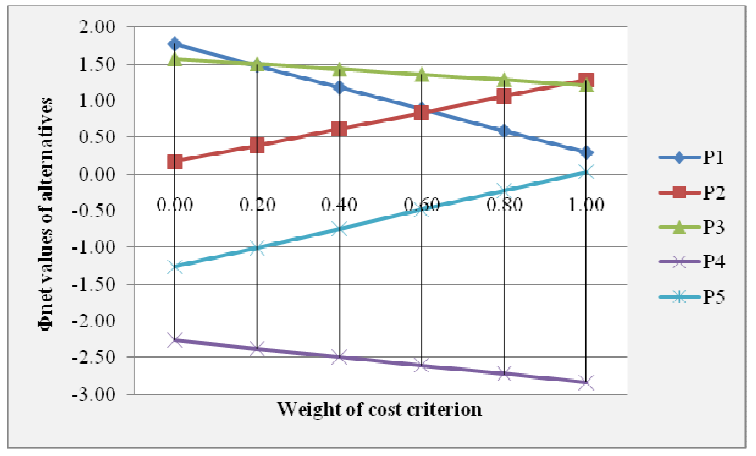

Figure 10. The change in the $\Phi^{\text {net }}$ values of alternatives with the change in the weight of cost criterion

After the investigation on sensitivity analysis, it can be said that the evaluations are sensitive to the weights of the criteria. Following the sensitivity analyses phase, the results are presented to the DMT and DMT found convenient to buy the best alternative which is P3.

\section{Conclusion}

In this study, a new approach which combines modified DELPHI technique- fuzzy AHP-fuzzy PROMETHEE techniques is utilized. Considering the importance of the criteria determination phase, a systematic approach, modified DELPHI method, is preferred. Before the application of this method, criteria alternatives are determined using current MTS literature and the method started with a pre-selected amount of criteria. This modification provides us an important time advantage. Following the criteria determination phase, fuzzy AHP is utilized for the criteria weights' calculations and alternative press machines are evaluated via fuzzy PROMETHEE methodology. Well structured criteria determination phase, consideration of the fuzziness inherent to the decision making environment, and user friendliness coming from the linguistic evaluations are the main advantages of the proposed methodology. For the future researches this methodology can also be easily applied to the other application areas both in manufacturing and service sectors.

\section{Acknowledgements}

The authors thank to Dr. Batuhan Kocaoğlu from Inka Fixing Corporation for his contribution to this study.

\section{References}

1. M. T. Tabucanon, D. N. Batanov, D. K. Verma, Intelligent decision support system (DSS) for the selection process of alternative machines for flexible manufacturing systems (FMS), Computers in Industry, 25(1994)131-143.

2. F. T. S. Chan, R. W. L. Ip, H., Lau, Integration of expert system with analytic hierarchy process for the design of material handling equipment selection system, Journal of Materials Processing Technology, 116 (2-3) (2001) 137145.

3. M. Yurdakul, AHP as a strategic decision-making tool to justify machine tool selection, Journal of Materials Processing Technology, 146 (3) (2004) 365-376.

4. C. W. Chang, C. - R. Wu, C. - T. Lin, H. -C. Chen, An application of AHP and sensitivity analysis for selecting the best slicing machine, Computers \& Industrial Engineering, 52 (2) (2007) 296-307.

5. E. Çimren, B. Çatay, E. Budak, Development of a machine tool selection system using AHP, Journal of International Journal of Advanced Manufacturing Technology, 35 (2007) 363-376.

6. Z. Ayag, R.G. Özdemir, A fuzzy AHP approach to evaluating machine tool alternatives, Journal of Intelligent Manufacturing, 17 (2) (2006) 179-190.

7. T. L. Saaty, The Analytic Hierarchy Process (New York: McGraw- Hill, 1981). 
8. S. Onut, S. S. Kara, T. Efendigil, A hybrid fuzzy MCDM approach to machine tool selection, Journal of Intelligent Manufacturing, 19 (2008): 443-453.

9. C. W. Chang, C.-R. Wu, H.-C. Chen, Using expert technology to select unstable slicing machine to control wafer slicing quality via fuzzy AHP, Expert Systems with Applications, 34 (3) (2008) 2210-2220.

10. O. Duran, J. Aguilo, Computer-aided machine-tool selection based on a Fuzzy-AHP approach, Expert Systems with Applications, 34 (3) (2008) 1787-1794.

11. M. R. Abdi, Fuzzy multi-criteria decision model for evaluating reconfigurable machines, International Journal of Production Economics, 117 (2009) 1-15.

12.Z. Ayă̆, R.G. Özdemir, An intelligent approach to machine tool selection through fuzzy analytic network process, Journal of Intelligent Manufacturing, (in press).

13. M. Dagdeviren, Decision making in equipment selection: an integrated approach with AHP and PROMETHEE, Journal of Intelligent Manufacturing, 19 (4) (2008) 397406.

14. R.U. Bilsel, G. Buyukozkan, D. Ruan, A fuzzy preferenceranking model for a quality evaluation of hospital web sites. International Journal of Intelligent Systems, 21 (11) (2006) 1181-1197.

15. F. Ulengin, Y.İ. Topçu, Ş.Ö. Şahin, An Integrated decision aid system for Bosporous water-crossing problem, European Journal of Operational Research, 134 (2001)179-192.

16. G. Tuzkaya, B. Gülsün, C. Kahraman, D. Özgen, An integrated fuzzy multi-criteria decision making methodology for material handling equipment selection problem and an application, Expert Systems with Applications, 37(4) (2010) 2853-2863.

17. A. Hartman, Reaching consensus using the Delphi technique, Educational Leadership, 38(6) (1981) 495-497.

18. W. C. Sung, Application of Delphi method. A qualitative and quantitative analysis to the healthcare management, Journal of Healthcare Management, 2 (2) (2001) 11-19.

19. A.T. Gumus, Evaluation of hazardous waste transportation firms by using a two step fuzzy-AHP and TOPSIS methodology, Expert Systems with Applications, 36 (2) (2009) 4067-4074.

20. R.L. Custer, J.A. Scarcella, B.R. Stewart, The modified Delphi Technique: A rotational modification, Journal of Vocational and Technical Education, 15(2) (1999).

21. C.-R. Wu, C.-T. Lin, H.-C. Chen, Integrated environmental assessment of the location selection with fuzzy analytical network process, Quality\&Quantity, 43 (3) (2007) 351-380.

22. S. P. Robbins, Management (New Jersey: Prentice Hall, 1994).

23. J. W. Murry, J. O. Hammons, Delphi: A versatile methodology for conducting qualitative research, Review of Higher Education, 18(4) (1995) 423-436.

24. C.-T. Chen, A fuzzy approach to select the location of the distribution center. Fuzzy Sets and Systems, 118 (1) (2001) 65-73.

25. T.-C. Wang, T.-H. Chang, Application of TOPSIS in evaluating initial training aircraft under a fuzzy environment, Expert Systems with Applications, 33 (4) (2007) 870-880.

26. A. Kengpol, C. O'Brien, The development of a decision support tool for the selection of advanced technology to achieve rapid product development, International Journal of Production Economics, 69 (2) (2001)177-191.

27. R. M. Yusuff, P. K. Yee, M. S. J. Hashmi, A preliminary study on the potential use of the analytical hierarchical process (AHP) to predict advanced manufacturing technology (AMT) implementation, Robotics and Computer Integrated Manufacturing, 17 (2001) 421-427.

28. Y.T. Abdul-Hamid, A.K. Kochhar, M.K. Khan, An analytic hierarchy process approach to the choice of manufacturing plant layout, Proceeding of Institute of Mechanical Engineers, Part B. 213 (4) (1999) 397-406.

29. K. Hafeez, Y.-B. Zhang, N. Malak, Determining key capabilities of a firm using analytical hierarchical process, International Journal of Production Economics, 76 (1) (2002) 39-51.

30. D.-Y. Chang, Theory and methodology: Application of the extent analysis method on fuzzy AHP, European Journal of Operational Research, 95 (1996) 649-655.

31. K.-J. Zhu, Y. Jing, A discussion on extent analysis method and application of fuzzy AHP, European Journal of Operational Research, 116 (2) (1999) 450-456.

32. U.R. Tuzkaya, S. Onut, A fuzzy analytic network process based approach to transportation-mode selection between Turkey and Germany: A case study, Information Sciences, 178 (15) (2008) 3133-3146.

33. M. Sugeno, An Introductory survey on fuzzy control. Information Sciences, 36 (1985) 59-83.

34. R.R. Yager, On a general class of fuzzy connectives, Fuzzy Sets and Systems, 4 (1980) 235-242.

35. R. R. Yager, A Procedure for Ordering Fuzzy Subsets of the Unit Interval, Information Sciences, 24 (1981) 143161. 
36. G. Büyükozkan, T. Ertay, C., Kahraman, D. Ruan, Determining the importance weights for the design requirements in the house of quality using the fuzzy analytic network approach, International Journal of Intelligent Systems, 19 (5) (2004) 443-461.

37. J. P. Brans, B. Mareschal, P. Vincke, PROMETHEE: A new family of outranking methods in MCDM. In J.P Brans (ed.), Operational Research IFORS 84 (Amsterdam: North-Holland, 1984), pp. 477-490.

38. J. P. Brans, P. Vincle, A preference ranking organization method. Management Science, 31 (6) (1985) 647-656.

39. J. P. Brans, P. Vincke, B. Mareschal, How to select and how to rank projects: The PROMETHEE method, European Journal of Operational Research, 24 (1986) 228238.

40. A. Albadvi, S.K. Chaharsooghi, A. Esfahanipour, Decision making in stock trading: An application of PROMETHEE, European Journal of Operational Research, 177 (2) (2007) 673-683.

41. C. Macharis, J. Springael, K. de Brucker, A. Verbeke, PROMETHEE and AHP: the design of operational synergies in multicriteria analysis. Stengthening PROMETHEE with ideas of AHP, European Journal of Operational Research, 153 (2) (2004) 307-317.

42. J. Geldermann, T. Spengler, O. Rentz, Fuzzy outranking for environmental assessment. Case study: iron and steel making industry, Fuzzy Sets and Systems, 115 (1) (2000) 45-65.

43. G. Vego, S. Kucar-Dragicevic, N. Koprivanac, Application of multi-criteria decision-making on strategic municipal solid waste management in Dalmatia, Croatia, Waste management, 28 (11) (2008) 2192-2201.

44. U.R. Tuzkaya, Evaluating the environmental effects of transportation modes using an integrated methodology and an application, International Journal of Environmental Science and Technology, 6 (2) (2009) 277-290.

45. M. Goumas, V. Lygerou, An extension of the PROMETHEE method for decision making in fuzzy environment: Ranking of alternative energy exploitation projects, European Journal of Operational Research, 123 (3) (2000) 606-613.

46. W.-C. Chou, W.-T. Lin, C.-Y. Lin, Application of fuzzy theory and PROMETHEE technique to evaluate suitable ecotechnology method: A case study in Shismen Reservoir Watershed, Taiwan, Ecological Engineering, 31 (4) (2007) 269-280.

47. Tuzkaya, G., Ozgen, A., Ozgen, D., Tuzkaya U.R., Environmental performance evaluation of suppliers: A hybrid fuzzy multi-criteria decision approach, International Journal of Environmental Science and Technology, 6 (3) (2009) 477-490.

48. C. Kahraman, T. Ertay, G. Buyukozkan, A fuzzy optimization model for QFD planning process using analytic network approach, European Journal of Operational Research, 171 (2) (2006) 390-411.

49. Tuzkaya, G., Gülsün, B., Evaluating centralized return centers in a reverse logistics network: An integrated fuzzy multi-criteria decision approach, International Journal of Environmental Science and Technology, 5 (3) (2008) 339352. 